\section{ICMC 2005 Reviews}

ESMuC Barcelona, Spain

Tuesday, 6 September 2005, Noon Concert (ESMuC Concert Hall)

by Felipe Otondo

The first tape piece of this concert, Iron Emerald by Andrew Cizink, was developed spatially in an interesting way in terms of the use of the timbre employed in the piece, which fit well in the wide room where the concert took place. Unfortunately, the piece evolved in a very predictable and simplistic way towards a very predictable climax.

The second tape piece of the concert, Sleep Driver by Martin Stig Andersen, showed a clever use of long transitions of very steady sounds in a sort of meditative way. The audience seemed to like the gentle character of the piece and its calm pace. Unfortunately, the sound projection of the piece was not at the level of the quality of the sound material, because it created a very steady and fixed spatialisation.

The next piece, Litania for saxophone, guitar and tape by João Pedro Oliveira, was probably the best piece of the concert. The composer made an effective use of the synthesized tape sounds, creating diverse types of interactions with the natural sounds of the instruments, contrasting their sound most of the time, and blending them in timbre and space at certain moments during the piece. The performance of the players (Sergi Rovira, saxophone and Carles Guisado, guitar) lacked a bit of naturalness, and at moments it became clear that the performers were just waiting for cues to play their part. There was no vivid sense of integration of the tape and the instruments.

The fourth piece of the concert was the tape piece L'uomo by Massimo Fragalà. This piece, based on texts as well as diverse sonorities and theatrical approaches of the voice, resembled pieces by Nono and Berio of the sixties and seventies. The piece worked quite well, creating dramatic and hilarious situations where the text worked as a framework and a sort of vehicle for dramatic voice gestures. This was a simple piece structurally, but it was very effective in its use of the material.

The fifth piece of the concert was the tape piece $A$ romance of rust by Antonio Ferreira. This acousmatic piece explored different types of timbral nuances of sound following constant evolutions in the transformations of sound. The piece showed an interesting combination of tonal sounds with other more granular sonorities.
The last piece of the concert was Javier Garavaglia's Ableitungen des Konzepts der Wiederholung (for Ala) for viola and computer, played by the composer himself. The piece, clearly based on the idea of repetition of a sequence performed by the instrument, showed to be very poor in its form, creating a development based on an eternal loop that went on and on. The relation between the sound of the instrument and the sound transformed through loudspeakers was never very clear. In brief, it was a very long and simplistic piece that seemed to be a rehearsal by a performer triggering sounds from a computer rather than a creative work where performer and computer really interact with each other. Unfortunately, this is a very common practice nowadays.

Wednesday, 7 September 2005, Noon

\section{Concert}

by Sile O'Modhrain

This lunchtime concert featured a wellbalanced program of works. Pieces for tape interleaved with pieces for acoustic instrument and/or live electronics. As for most of this year's concerts, the performers were, for the most part, local student ensembles.

Vivencias - Beatriz Ferreyra - Tape Vivencias was commissioned for Musiques \& Recherches in Belgium in 2001. In Spanish, the word means experiences that contribute to the personality of the whole being. Sonically, events emerge from a context of filtered noise, making explicit as they do so the fine distinction

between tightly filtered noise bands and pitches.

Signals - Michael Klingbeil

Contrast String Quartet (Jordi Claret, Claudia Farrés, Elias Porter, Noemí Rubio), Michael Davidov, piano and MIDI keyboard

This piece for string quartet and piano/ keyboard explores the boundaries between sustained clusters of tones and the clustered overtones of a piano pitch drawn out through the use of electronic effects. The musicians, a local student string quartet, handled the music with great care and maturity of approach.

in-s-cape II - Aikaterini Tzedaki - Tape As stated by the composer, the aim of this composition is the sonic realization of a journey through imaginary soundscapes. An imaginary soundscape is a type of inner soundscape (in-scape).

Ajunennuline - Shawn Pinchbeck - Tape This piece derives its material from a collection of found sounds with textural properties that are surprising in their relatedness - drills, cats growling, dogs barking and corks popping. The title Ajulennuline is a word that the composer made up, but derives from the Estonian 
word "linnulennuline" or "bird's-eye view." Literally, it translates as "brain flying like a bird," and is intended to capture the act of the mind drifting from one thought to another. In this case, the thoughts are related through the sonic environment they provoke.

Stream - Arne Eigenfeldt - Computer and data glove

Streamisanexploration of differentmeanings of the title: moving water, moving people, moving data. It is a journey in which the listener inhabits the stream in its changing meanings, observing the sonic environment through which the stream passes as both sources of sound and their reflections on the surfaces of imaginary objects. As the piece progresses, the meaning of 'stream' becomes more abstract, and the sound environment becomes more complex.

Psalm 06 - Douglas Scott - Tape

Psalm 06 is a portrait in sound of the sixth penitential psalm from the Old Testament. The source material for the entire piece is the text of the psalm, recited in both English and Latin by Denise

Gill. Its overlapping sections mirror the division of the text into ten two-line stanzas. However, this is not a setting of the text in a traditional sense. The accompanying material is derived from the vocal material using a granular synthesis approach, and the result is a texture where the division between vocal material and accompanying

\section{texture is extremely fluid.}

Fluctuations - Seung Hye Kim - Flute and live electronics

Finally, Fluctuations explores the sonic world on the borders of pitched and unpitched flute tones.

\section{Thursday, 8 September 2005, afternoon concert \\ by John ffitch}

What I privately thought of as the evening concert took place in the large concert hall. The comfort of the seats contrasted with the uncomfortable bright blue backscreen behind the performers, which made looking at the performance a little of a trial.

The concert opened with Séparé et invisible by Yasuhiro Takenaka. The composer stated in the booklet that "the work describes the relationship between the saxophone part and the electronic part in accordance with that between the two worlds," but I did not read this until after the concert. It is a tribute to the work that my initial reaction was to appreciate the juxtaposition of the two streams; the sounds worked well together and managed that difficult task of unifying the physical and electronic within the same sound world. I was less convinced by the second section, and at times there seemed a resort to trite solutions, but this did not detract from the overall effect. I thought that at about 15 minutes it was perhaps too long. My notes comment on the ending: there appeared to be an extraneous voice, out of character with the previous sounds, but this could have been outside the auditorium.

The second work was for guitar and tape, Sol y sombra...L'espace des spectres, a joint creation by Francis Dhomont and the performer Arturo Parra. This work also contrasted the tape component with a traditional Spanish guitar sound, although the tape sounds were created from samples of the same guitarist. In the concert, the relationship between these strands was not clear, and I was not convinced that they belonged together. I also failed to understand the structure of the piece and so was disappointed overall. I could of course appreciate that the playing was of a very high standard.

Clandestine Parts by Paulina Sundin was the high point of the concert for me. A tape work that started with a slow, thoughtful passage clearly established the sound world, and when this later changed to a fast section the unity continued, maintaining interest while continuing to have something to say. The sounds were all well crafted; this is definitely a work I would like to hear again.

There then followed two works that used the saxophonist Xelo Giner. Stefan Klaverdal's
Prayer of a King for alto saxophone and computer was a gentle piece, with the saxophone dominant, being enhanced by computer processing. Perhaps the hall was too large for this work, which would have been better in a chamber music setting. Its gentle sounds were too much for my neighbour, who slept through it.

Un caracol manchado by Alfonso Garcia de la Torre was the other piece for saxophone and electronics. I had problems perceiving where the electronic component was for much of the opening section, and while there were a number of nice moments, I was left with a feeling of missing the unity of the whole work. Seeking clarification in the program booklet, I found that the notes were in Spanish, a language I do not know, and so I remain uncertain what was intended.

The concert ended with Panayiotis Kokoras's Shatter Cone. The work for violin and tape, played by Jordi Claret, explored the way in which the violin's sounds are created, and the program notes suggest that the tape sounds originate from the violin. The processing was such that sounds were quite distant from the live instrument; there were uses made of string-like glissandi in the tape part, but I lost the thread rather too soon. The piece ended with what I took as a joke, with a burp after the violin had ended. 
Throughout the concert, Xelo Giner played the saxophones with great versatility and conviction.

Areview of this concertwould be incomplete without mentioning an aspect of all the 19:30 concerts: there was no interval and minimal gaps between the pieces. Preparing for the next work by checking the title or program notes was not possible unless one had brought a torch. My notes on some of these pieces were written in total darkness and so hard to read. In ICMC 2003 the conference pen incorporated a light, and I wished I had that with me to record more fully my impressions.

\section{IGMG 2006 Reviews}

Tulane University

New Orleans, Louisiana, USA

Concert V: Tuesday, 7 November 1:30pm, McAllister Auditorium by fon Appleton and Daniel Shapira

Path to the Serene - Yuriko Kojima

Japanese composer Yuriko Kojima's chamber work for the Azure Ensemble was beautifully performed. It was a lovely, gentle, colorful, post-Debussy work without any significant appearance of computer-generated sound or modification of the flute, violin, cello, harp or piano.

Balacoire \#15 - Jeremy Baguyos

Goelle Leandre's vocal techniques are the source of Jeremy Baguyos's Balacoire \#15. An arresting and highly original work, it suggests life in a surrealistic bird sanctuary. Sometimes the music alternated between the effective use of silence and highly humorous organic sounds. Perhaps the looping audio was excessive, even if the repetition was intentional.

Fragmentary Seven - Haruka Hirayama A rising star of Japanese computer music is Harika Hirayama. Her works have been recognized in competitions and by inclusion in recent ICMC concerts. Her virtuoso double bass solo was superbly performed. The inharmonic stringlike attacks were striking and sometimes even grotesque. Noticeable in many works like this one performed at the conference was the return of feedback techniques updated through granular synthesis.

\section{Das Bleierne Klavier - Hans Tutschku}

Composerand pianist Tutschku's 1 1-minute work seemed to last an eternity. Filled with the tired gestured of the European avantgarde, this second-rate import featured the most simplistic delay and processing modifications of the strident piano timbres. Harvard University, Tutschku's home, has proved itself again to be an ultraconservative bastion of "modernism." Many in the audience were angered by being subjected to this drudgery.

Seven Lonely Rivers - Kristi McGarity A rising star of the American computer music scene is oboist-composer Kristi McGarity. Her work for oboe and tape was a wandering, impressionistic, modal melody over a tonic pad with contrasting sections of wildlife sounds. Verging on new-age ambiance, it occasionally breaks out in unexpected and adventurous ways.

les jeux sont faits - Tommaso Perego Violinist Viktoria Horti of the Onix 